\title{
Effect of $\mathrm{ZrO}_{2}, \mathrm{Al}_{2} \mathrm{O}_{3}$ and $\mathrm{La}_{2} \mathrm{O}_{3}$ on cobalt-copper catalysts for
}

\section{higher alcohols synthesis}

\author{
Zi Wang, James J. Spivey*
}

Department of Chemical Engineering, Louisiana State University, Baton Rouge, LA 70803, USA

*Corresponding author at: Department of Chemical Engineering, Louisiana State University, S. Stadium Drive, Baton Rouge, Louisiana, 70803, USA

Email: ijspivey@Isu.edu Phone: 225-578-3690 Fax: 225-578-1476 


\section{Graphical Abstract to}
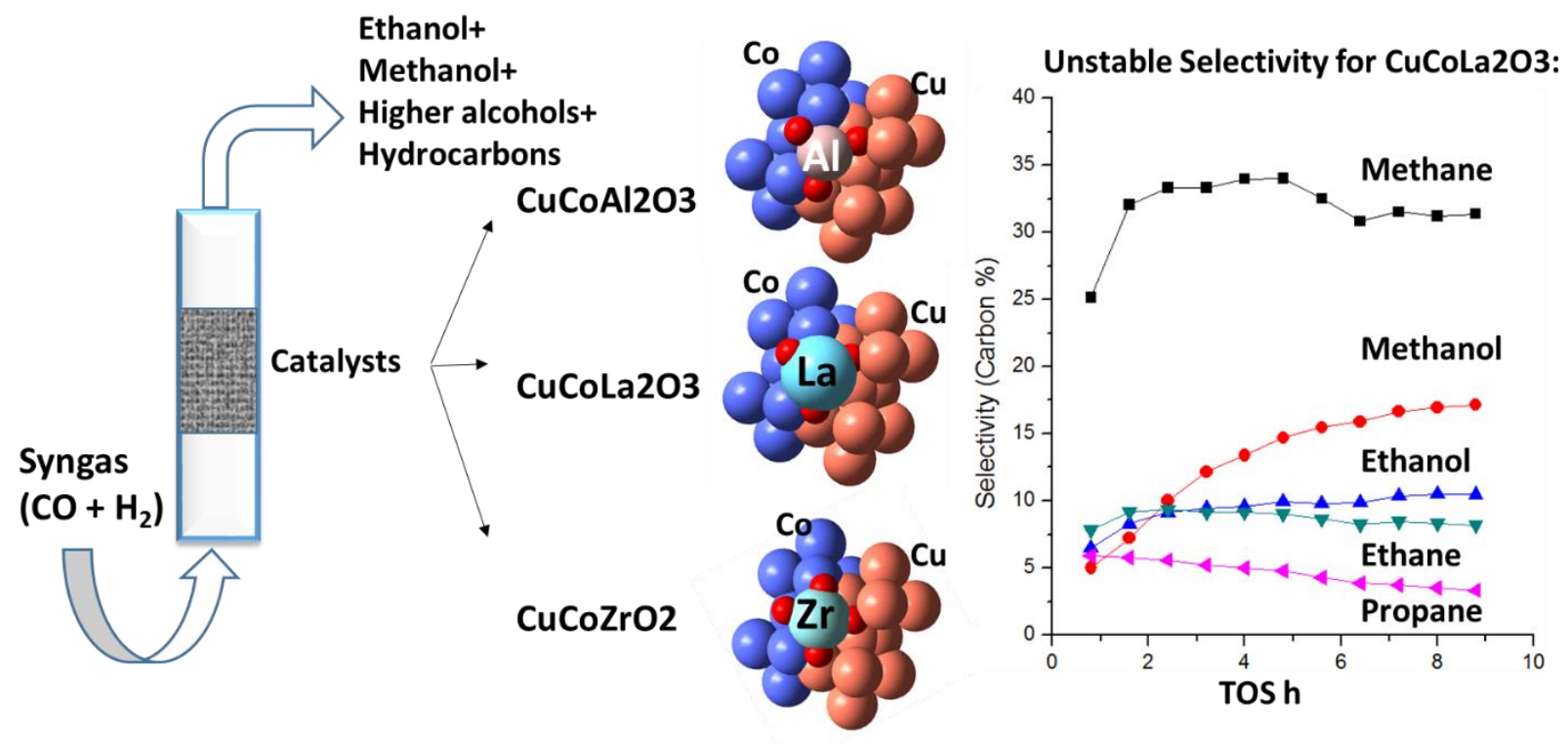


\begin{abstract}
Three cobalt-copper catalysts singly promoted with $\mathrm{La}, \mathrm{Zr}$, or Al were studied for catalytic conversion of syngas to higher alcohols. The properties of the promoted catalysts have been characterized by TPR, XRD, XPS and BET. CO hydrogenation was carried out in a plugflow reactor under 30 bar, $\mathrm{GHSV}=36000 \mathrm{scc} / \mathrm{g}_{\mathrm{cat}} / \mathrm{h}, \mathrm{H}_{2} / \mathrm{CO}=2$, and $250^{\circ} \mathrm{C}$ at differential conversions. The catalyst activity and selectivity to higher alcohols are greatest on CuCoLa2O3: ethanol selectivity $10.5 \%$ at a conversion of $0.76 \%$. During 9 hours of time-on-stream, CO conversion decreased on CuCoLa2O3 while methanol and higher alcohol selectivity increased. The behavior on $\mathrm{CuCoZrO} 2$ and $\mathrm{CuCoA} 12 \mathrm{O} 3$ were different. On these two catalysts, $\mathrm{CO}$ conversion and selectivity reached a near-steady state much more quickly than CuCoLa2O3. These results suggest changes on $\mathrm{CuCoLa} 2 \mathrm{O} 3$ that increase the selectivity for oxygenates continue with time, at least over the time scale investigated here.
\end{abstract}

Key words: Higher alcohols synthesis; Syngas; Cobalt; Copper; Metal oxide promoters; Modified Fischer-Tropsch catalysts 


\section{Introduction}

Increasing demand has focused on renewable and environmentally benign energy sources for the catalytic conversion of biomass-, natural gas-, and coal-derived syngas to liquid fuel. An alternative to producing long-chain hydrocarbon products via Fischer-Tropsch (FT) synthesis is the conversion of syngas into more valuable higher alcohols. These higher carbon-number alcohols can be used as hydrogen carriers for fuel cells, or as additives directly blended into gasoline $[1,2]$. However, additional research is required before extrapolating lab-scale studies to industry-level application. Currently, it is difficult to commercialize this process due to relatively low activity, yield and stability of the catalysts. Rh-based catalysts have shown high yield to higher alcohols in CO hydrogenation, with net yields typically ranging from 10-20\% [3-6]. However, the relatively high price of these catalysts has limited the development of more practical processes [7]. Among all the non-noble metal based catalysts, cobalt-copper modified Fischer Tropsch catalysts are promising substitutes for noble metal-based catalysts [8-11].

Recent studies have shown that promoters can increase the selectivity of $\mathrm{Co}-\mathrm{Cu}$ catalysts to oxygenates. The Institut Francais du Petrole (IFP) filed a number of patents on the development of cobalt-copper based modified Fischer Tropsch catalysts for higher alcohols synthesis $[8,12-16]$. Under moderate operating conditions, the selectivity to higher alcohols ranged from $20 \%$ to $70 \%$. The ethanol yield over $\mathrm{Cu}$-Co-based catalysts ranged from 100 to 300 $\mathrm{mg} /(\mathrm{g} \cdot \mathrm{cat} \cdot \mathrm{h})$, suggesting commercial interest in these catalysts. Following the IFP work, a wide range of studies on $\mathrm{Co}-\mathrm{Cu}$ bimetallic catalysts are reported to further increase the selectivity to higher alcohols $[10,17,18]$. Researchers correlate the activity and selectivity of the catalysts with the type of synthesis method, the alkali promoters used, and physicochemical properties of 
the catalysts such as metal particle sizes, dispersions, and the atomic proximity of cobalt and copper.

Specifically, metal oxide promoters such as $\mathrm{ZrO}_{2}, \mathrm{La}_{2} \mathrm{O}_{3}$ and $\mathrm{Al}_{2} \mathrm{O}_{3}$ greatly affect the reduction and product selectivity of cobalt-copper-based catalysts. For instance, $\mathrm{ZrO}_{2}$ assists the reduction of $\mathrm{Co}^{2+}$ species to metallic cobalt for $\mathrm{CO}$ hydrogenation, and $\mathrm{ZrO}_{2}$ promoted catalysts show increased selectivity to ethanol[19]. According to Lebarbier et al.[20] , $\mathrm{La}_{2} \mathrm{O}_{3}$-supported cobalt catalyst reached almost complete cobalt reduction after $\mathrm{H}_{2}$ treatment, and cobalt dispersion on $\mathrm{La}_{2} \mathrm{O}_{3}$ supported catalyst was higher than those on activated carbon and $\mathrm{Al}_{2} \mathrm{O}_{3}$. Alumina-supported cobalt FT catalysts show greater stability, high activity and strong metalsupport interactions comparing with $\mathrm{TiO}_{2}$ and $\mathrm{MgO}[21,22]$. A study of alumina-supported copper-cobalt bimetallic catalysts for $\mathrm{CO}$ hydrogenation by Wang et al.[23] reported increased interaction between cobalt and copper particles on a $\gamma-\mathrm{Al}_{2} \mathrm{O}_{3}$ supported catalyst compared with unpromoted catalysts, which improved the selectivity of the catalysts to higher alcohols. Past work shows that the choice of the metal oxide promoters greatly influences catalyst morphology, cobalt-copper interaction, and reduction or reaction performance. These metal oxides also promote cobalt copper catalysts in activity and selectivity to ethanol and other oxygenates.

Therefore, the purpose of this work is to study zirconia, alumina and lanthana as metal oxide promoters for cobalt-copper higher alcohols synthesis catalysts. In the present study, cobalt and copper salts are coprecipitated with the third metal salt ( $\mathrm{Zr}, \mathrm{Al}$ or $\mathrm{La})$ to synthesize three promoted catalysts, denoted as $\mathrm{CuCoZrO} 2, \mathrm{CuCoA} 12 \mathrm{O} 3$, and CuCoLa2O3. Coprecipitated metal oxides serve as supports to maintain highly dispersed metal clusters that contain both cobalt and copper particles. The promoting effects of these metal oxides are measured by $\mathrm{H}_{2}$ TemperatureProgrammed Reduction, X-Ray Diffraction, X-Ray Photoelectron Spectroscopy, BET surface 
area, and $\mathrm{CO}$ hydrogenation activity studies. The aim of this study is to directly compare the promoting effects of the metal oxides on the activity, selectivity, and stability of these catalysts for higher alcohols synthesis.

\section{Experimental}

\subsection{Catalyst Preparation}

Catalysts were prepared by $\mathrm{pH}$-coprecipitation method. In the coprecipitation method, cobalt nitrate, copper nitrate and corresponding metal salts $\left(\mathrm{Al}(\mathrm{NO})_{3} \bullet 9 \mathrm{H}_{2} \mathrm{O}, \mathrm{ZrO}\left(\mathrm{NO}_{3}\right)_{2}\right.$, or $\left.\mathrm{La}\left(\mathrm{NO}_{3}\right)_{3} \cdot 6 \mathrm{H}_{2} \mathrm{O}\right)$ were dissolved together in deionized water. The molar ratio of $\mathrm{Cu}$ nitrite to Co nitrite to metal salts was kept at 2:2:1. The solution were titrated to $100 \mathrm{ml}$ water under magnetic stirring at $80^{\circ} \mathrm{C}$. Meanwhile, a solution of ammonia carbonate was titrated in order to maintain the $\mathrm{pH}$ at $7.00 \pm 0.2$. After the titration, the solution was aged at room temperature for 6 hours, then the solid was recovered by washing and filtration. Collected precipitates were dried at $90{ }^{\circ} \mathrm{C}$ for 24 hours, then calcined at $500^{\circ} \mathrm{C}$ for $3 \mathrm{~h}$ under air flow. The samples are denoted as $\mathrm{CuCoA12O} 3, \mathrm{CuCoLa} 2 \mathrm{O} 3$ and $\mathrm{CuCoZrO} 2$ to demonstrate the promoters used in the catalysts.

\subsection{Composition and Surface Area}

The compositions of the calcined catalysts were determined by inductively coupled plasma optical emission spectrometry (ICP-OES) method using a Perkin Elmer 2000 DV ICPoptical emission spectrometer.

BET surface area of freshly calcined catalyst were determined by $\mathrm{N}_{2}$ adsorption at $196^{\circ} \mathrm{C}$. Prior to analysis, the samples were treated in helium flow at $150^{\circ} \mathrm{C}$ for 30 minutes to remove the moisture. A flow BET procedure using $\mathrm{N}_{2}$ concentrations of $10 \%, 20 \%$, and $30 \%$ in a He carrier was used in an Altamira AMI-200 system. 


\subsection{Hydrogen Temperature Programmed Reduction $\left(\mathrm{H}_{2}\right.$-TPR)}

$\mathrm{H}_{2}$-TPR was done on 50mg of calcined catalyst in an Altamira AMI-200 system. 50mg of calcined catalysts were pretreated in Helium flow at $150^{\circ} \mathrm{C}$ for $30 \mathrm{~min}$ to remove moisture. Reducing gas of $50 \mathrm{sccm} 10 \% \mathrm{H}_{2} / \mathrm{Ar}$ flowed through the reactor as the temperature increased at $5^{\circ} \mathrm{C} /$ min to $550^{\circ} \mathrm{C}$. A thermal conductivity detector (TCD) monitored the consumption of $\mathrm{H}_{2}$. A calibration using TPRs of 20,35 and $50 \mathrm{mg} \mathrm{Ag}_{2} \mathrm{O}$ allowed quantitative analysis of hydrogen uptake by the catalysts.

\subsection{In situ X-Ray Diffraction (XRD)}

XRD measurements of the catalysts were done at the Center for Nanophase Materials Science at Oak Ridge National Laboratory. Catalyst Samples were loaded into an Anton Paar XRK900 reactor chamber. A $4 \% \mathrm{H}_{2} / \mathrm{He}$ gas was flowed through the chamber to conduct the reduction process, and a PANalytical X'Pert Pro MPD diffractometer with $\mathrm{Cu}$ Ka radiation $(\lambda=0.15406 \mathrm{~nm})$ was used to record XRD patterns at different temperatures. The spectra were collected from $15^{\circ}$ to $70^{\circ}$ with a step size of $0.0167^{\circ}$. X'pert HighScore Plus were used to identify phases by the Search \& Match feature.

\subsection{X-Ray Photoelectron Spectroscopy (XPS)}

XPS experiments on calcined catalysts were performed on a Kratos AXIS 165 X-Ray

Photoelectron Spectrometer using monochromatic $\mathrm{Al} \mathrm{K} \alpha_{1}$ radiation $(h v=1486.6 \mathrm{eV}$, intrinsic linewidth $0.3 \mathrm{eV})$. The pressure in the analysis chamber was kept between $10^{-8}$ and $10^{-9}$ Torr during the experiments. Survey spectra with a pass energy of $160 \mathrm{eV}$ were taken on each sample prior to the measurement to check correct sample alignment. High resolution scans of $\mathrm{Co} 2 \mathrm{p}, \mathrm{Cu}$ 2p, C 1s, O 1s, Al 2p, La 3d and Zr 3d were recorded with a pass energy of $40 \mathrm{eV}$. C 1s peak at $284.8 \mathrm{eV}$ were used as known standard to calibrate binding energy scale. 


\subsection{Reaction Studies}

Reactions were carried out in an Altamira AMI-200R-HP system equipped with a 1/4-in. glass-lined stainless steel reactor tube. $50 \mathrm{mg}$ of calcined sample was reduced in a mixture of $\mathrm{H}_{2}$ and $\mathrm{He}$ for 3 hours at a standard temperature $400^{\circ} \mathrm{C}$. After reduction, the reactor was cooled to room temperature in $\mathrm{He}$, then pressurized to $30 \mathrm{bar}$ and heated to $250^{\circ} \mathrm{C}$. At this point, $\mathrm{He}$ is switched by a simulated-syngas flow (space velocity $=36000 \mathrm{scc} / \mathrm{g}_{\mathrm{cat}} / \mathrm{h}, \mathrm{H}_{2} / \mathrm{CO}=2$ ). Products were analyzed in a Shimadzu GC2014 gas chromatograph with flame ionization and thermal conductivity detectors (FID and TCD). Reaction data was measured continuously until the results are steady.

The reactions were carried out at differential conversion ( $\mathrm{CO}$ conversion $<3 \%)$. This minimizes deactivation as well as temperature and concentration gradients in the reactor. This also eliminates the need to capture and analyze a liquid, integral sample over extended periods of time, which does not measure any changes in the product composition with time.

\subsection{Temperature Programmed Oxidation (TPO) Coupled With Mass Spectroscopic Measurements on Used Catalysts} After the reaction, the samples were purged in $\mathrm{He}$ for 30 minutes at $25^{\circ} \mathrm{C}$. The reactor was then heated to $750^{\circ} \mathrm{C}$ at $15^{\circ} \mathrm{C} / \mathrm{min}$ in $30 \mathrm{sccm} 10 \% \mathrm{O}_{2} / \mathrm{He}$ flow. The profiles of $\mathrm{CO}_{2}$ evolution ( $\mathrm{m} / \mathrm{z}=44$ ) were collected by an Ametek Quadrupole MS.

\section{Results and Discussion}

\subsection{Composition and Surface Area} ICP-OES Sample composition and BET surface area results are listed in Table 1.

CuCoAl2O3 showed the highest surface area $\left(94.1 \mathrm{~m}^{2} / \mathrm{g}\right)$, while CuCoLa2O3 had the lowest surface area $\left(49.7 \mathrm{~m}^{2} / \mathrm{g}\right)$. Bulk Co and $\mathrm{Cu}$ composition by ICP-OES are shown in Table 1. Note that the molar ratios of $\mathrm{Co}: \mathrm{Cu}$ :Metal Oxides are intentionally kept as 2:2:1 for all three catalysts. 


\subsection{TPR}

Temperature programmed reduction profiles obtained for the three catalysts are shown in Figure 1.

All three catalysts displayed similar reduction behavior between $185^{\circ} \mathrm{C}$ to $250^{\circ} \mathrm{C}$. For $\mathrm{CuCoZrO} 2$, the first shoulder at $\sim 190^{\circ} \mathrm{C}$ is attributed to reduction of $\mathrm{CuO}$ to $\mathrm{Cu}^{0}$. The peak at around $200^{\circ} \mathrm{C}$ and the shoulder at $230^{\circ} \mathrm{C}$ correspond to the two-step reduction of $\mathrm{Co}_{3} \mathrm{O}_{4}$ to $\mathrm{CoO}$ and $\mathrm{CoO}$ to $\mathrm{Co}^{0}$. $\mathrm{CuCoAl} 2 \mathrm{O} 3$ has a similar reduction behavior. The broad shoulder from $250^{\circ} \mathrm{C}$ to $350^{\circ} \mathrm{C}$ in both $\mathrm{CuCoZrO} 2$ and $\mathrm{CuCoAl} 2 \mathrm{O} 3$ are due to the reduction of residual $\mathrm{CoO}$ to metallic cobalt.

The CuCoLa2O3 reduction profile is somewhat different. Although the same reduction of copper at $\sim 190^{\circ} \mathrm{C}$ is seen, the feature at $215^{\circ} \mathrm{C}$ shows an asymmetric peak for $\mathrm{CuCoLa} 2 \mathrm{O} 3$, which can be assigned as the combination of $\mathrm{Co}_{3} \mathrm{O}_{4}$ to $\mathrm{CoO}$ and $\mathrm{CoO}$ to $\mathrm{Co}^{0}$ reduction. The broad shoulder above $250^{\circ} \mathrm{C}$, associated with the extended reduction of cobalt due to less easily reduced cobalt for the $\mathrm{Zr}$ - and Al-promoted catalysts, is not seen on CuCoLa2O3. This is probably because of higher dispersion of $\mathrm{Cu}$-Co particles and stronger interaction between cobalt and copper in La-promoted catalysts, consistent with the literature. The promoting effect of $\mathrm{H}_{2}$ reduction by hydrogen spillover mechanism associated with $\mathrm{La}_{2} \mathrm{O}_{3}$ has been reported on lanthanum promoted cobalt catalysts before[20], therefore, the possibility that $\mathrm{La}_{2} \mathrm{O}_{3}$ promoted the reduction of cobalt in $\mathrm{CuCoLa} 2 \mathrm{O} 3$ catalyst cannot be ruled out.

Table 2 shows the experimental and expected hydrogen consumption during the TPR. Reduction of cobalt and copper is essentially complete up to $250^{\circ} \mathrm{C}$ on all three promoted catalysts, with CuCoAl2O3 being slightly less reduced $(92.7 \pm 2.0)$ than for the other two $(97.5 \pm$ 1.2 and $96.4 \pm$ 1.6). This is consistent with literature that $\mathrm{ZrO}_{2}$ and $\mathrm{La}_{2} \mathrm{O}_{3}$ facilitate $\mathrm{H}_{2}$ reduction 
of cobalt and copper oxides, leading to more complete reduction of the $\mathrm{CuCoZrO} 2$ and the CuCoLa2O3 than the CuCoAl2O3 catalyst $[9,19]$.

\subsection{In situ X-ray Diffraction}

XRD patterns of the three catalysts during $\mathrm{H}_{2}$ - reduction are shown in Figure 2. For

$\mathrm{CuCoAl} 2 \mathrm{O} 3$, the fresh, calcined catalyst include $\mathrm{Co}_{3} \mathrm{O}_{4}$ and $\mathrm{CuO}$ (Figure. 2 (a)). At $200^{\circ} \mathrm{C}$, the intensity of the peaks for $\mathrm{Co}_{3} \mathrm{O}_{4}$ and $\mathrm{CuO}$ had decreased, and metallic phases at $43.2^{\circ}$ and $50.3^{\circ}$ begin to appear. Meanwhile, a peak at $61.8^{\circ}$ emerged, which indicates the existence of a $\mathrm{CoO}$ phase was apparent at $300^{\circ} \mathrm{C}$, but disappeared at $400^{\circ} \mathrm{C}$. Only metallic phases are present at $400^{\circ} \mathrm{C}$.

The results of the in-situ XRD combined with the TPR patterns clearly show that reduction of $\mathrm{CuO}$ starts at $\sim 185^{\circ} \mathrm{C}$. The expected reduction sequence of copper and cobalt oxides to reduced metals is apparent in the loss of the crystalline oxides and appearance of the reduced metals. The long shoulders from $250^{\circ} \mathrm{C}$ to $350^{\circ} \mathrm{C}$ in the $\mathrm{CuCoZrO} 2$ and $\mathrm{CuCoAl} 2 \mathrm{O} 3$ that are seen in the TPR are not easily distinguished in the XRDs from the $\mathrm{CuCoLa} 2 \mathrm{O} 3$. At $400^{\circ} \mathrm{C}$, all three catalysts are fully reduced. Based on the width of the peaks of all three catalysts, copper clusters are more crystalline than cobalt clusters, which are quite amorphous.

CuCoLa2O3 and $\mathrm{CuCoZrO} 2$ had reduction patterns similar to $\mathrm{CuCoA12O}$. CuCoLa2O3 had a tilted background due to a higher dispersion of $\mathrm{Co}_{3} \mathrm{O}_{4}$ and $\mathrm{CuO}$ clusters (Figure 2 (b)). This is consistent with the TPR results, which did not show a broad shoulder above $\sim 250^{\circ} \mathrm{C}$. $\mathrm{CuCoZrO} 2$ displayed minor $\mathrm{CuO}$ features below $200^{\circ} \mathrm{C}$, which indicates the existence of both crystalline and amorphous copper oxide in the calcined catalyst. Significantly, there is no peak that could be directly attributed to cobalt aluminate or lanthanum cobalt oxides, but the possibility of forming cobalt-metal oxides in the catalysts cannot be ruled out. 


\subsection{XPS}

XPS studies of calcined samples were carried out in order to study the chemical state of the elements at catalyst surface, and determine surface metal compositions. The XPS spectra of the three fresh, calcined catalysts for $\mathrm{Co}\left(2 \mathrm{p}_{3 / 2}\right)$ and $\mathrm{Cu}\left(2 \mathrm{p}_{3 / 2}\right)$ are shown in Figure $2(\mathrm{~d})$ and (e) respectively. Co $2 \mathrm{p}_{3 / 2}$ peak located at $779.3 \mathrm{eV}$ for all three samples, which shows that cobalt is in the form of $\mathrm{Co}_{3} \mathrm{O}_{4}$ on the surface $[18,19]$. The $\mathrm{Cu} 2 \mathrm{p}_{3 / 2}$ main peak is positioned at $933.6 \mathrm{eV}$ with a shake-up satellite peak accompanied at $942 \mathrm{eV}$, thus copper ions on the surface for all three catalysts are in the form of $\mathrm{CuO}$ [24], as expected.

Table 3 summarizes copper and cobalt binding energies of the samples surfaces. Surface and bulk $\mathrm{Cu} / \mathrm{Co}$ atomic ratios calculated by XPS and ICP respectively are also shown in Table 3 . Although $\mathrm{CuCoA} 12 \mathrm{O} 3$ and $\mathrm{CuCoLa} 2 \mathrm{O} 3$ show slightly higher $\mathrm{Cu} / \mathrm{Co}$ atomic ratio on the surface than in the bulk, these results indicate that all three samples are composed of relatively uniform particles with a constant atomic ratio of cobalt and copper.

\subsection{Catalyst Activity Test}

Figure 3 shows the $\mathrm{CO}$ conversion as a function of time-on-stream at $250^{\circ} \mathrm{C}$ and 30 bar. Note that all CO conversions are intentionally kept at differential CO conversion $(<3 \%)$ to avoid condensation (section 2.6).

$\mathrm{CuCoA} 12 \mathrm{O} 3$ had highest activity under reaction condition. While $\mathrm{CuCoZrO} 2$ and CuCoLa2O3 had much lower activity. $\mathrm{CuCoAl} 2 \mathrm{O} 3$ and $\mathrm{CuCoZrO} 2$ slightly lost activity in the first two hours of reaction, then reaching near steady-state after $2 \sim 3$ hours of operation. For CuCoLa2O3 catalyst, however, CO conversion decreased with time over the 9 hours of operation. 
Figure 4 shows the changes of product selectivity with time. For $\mathrm{CuCoZrO} 2$ and CuCoAl2O3, the selectivity to alcohols and $\mathrm{C}_{2+}$ products were relatively stable through 9 hours of reaction, whereas methane selectivity slightly increased with time. Nevertheless, CuCoLa2O3 displays more significant changes of the selectivity to $\mathrm{C}_{2+}$ products. The most striking fact is the increase of methanol and ethanol selectivity at $250^{\circ} \mathrm{C}$ with time. At this temperature, the selectivity to ethanol increased from $6.5 \%$ to $10.5 \%$ and the selectivity to methanol had increased from 5\% to $16.9 \%$ after 9 hours on stream. The increased alcohols selectivity is associated with a small decrease of ethane and propane selectivity.

CuCoLa2O3 shows increased selectivity of methanol and decreased selectivity of methane with time. Methane is synthesized from dissociated $\mathrm{CO}$ while methanol is formed from associatively adsorbed $\mathrm{CO}$ [25]. Therefore, the increase of methane and the decrease of methanol selectivity indicate the increase of associatively adsorbed $\mathrm{CO}$ and the decrease of dissociatively adsorbed $\mathrm{CO}$ with time.

The product selectivity distribution for the three catalysts over $9 \mathrm{hr}$ time-on-stream is shown in Table 4. At $250^{\circ} \mathrm{C}, \mathrm{CuCoLa} 2 \mathrm{O} 3$ catalyst showed highest selectivity to ethanol among the three catalysts, $\mathrm{CuCoZrO} 2$ and $\mathrm{CuCoAl} 2 \mathrm{O} 3$ had similar selectivity toward ethanol, $\mathrm{C}_{2+}$ oxygenates and $\mathrm{C}_{2+}$ hydrocarbons. Table 4 shows that CuCoLa2O3 is less selective to $\mathrm{C}_{2+}$ hydrocarbons, which means Fischer Tropsch synthesis in the reaction is inhibited on CuCoLa2O3, leading to higher methanol and ethanol selectivity of CuCoLa2O3 catalyst. In general, $\mathrm{CuCoAl} 2 \mathrm{O} 3$ has properties very similar to traditional Fischer-Tropsch catalysts, with a high selectivity to methane and $\mathrm{C}_{2+}$ hydrocarbons. $\mathrm{CuCoZrO} 2$ also favors $\mathrm{C}_{2+}$ hydrocarbons, but produces more $\mathrm{C}_{2+}$ oxygenates than $\mathrm{CuCoAl2O}$. This could be due to the reason that $\mathrm{ZrO}_{2}$ 
provide more basic sites than $\mathrm{Al}_{2} \mathrm{O}_{3}$, which suppress hydrocarbon selectivity and favor oxygenates formation[26].

CuCoLa2O3 shows significantly greater selectivity to methanol and $\mathrm{C}_{2+}$ oxygenates than $\mathrm{CuCoZrO} 2$ or $\mathrm{CuCoAl} 2 \mathrm{O} 3$. There is a difference between the formation of methanol and $\mathrm{C} 2+$ oxygenates. Methanol is formed by the hydrogenation of associatively adsorbed $\mathrm{CO}$, while $\mathrm{C} 2+$ oxygenates are formed by the hydrogenation of atomically adjacent sites, one of which is a $\mathrm{CHx}$ moiety produced from dissociatively adsorbed $\mathrm{CO}$ and one of which is formed by associatively adsorbed $\mathrm{CO}$. These two moieties then form the first $\mathrm{C}-\mathrm{C}$ bond, from which $\mathrm{C} 2+$ oxygenates are produced[2, 27]. The relative rates of the formation of these two moieties produces the observed product selectivities----e.g. C2+ oxygenates. The relatively high methane selectivity is consistent with the mechanism in which hydrogenation of dissociatively adsorbed $\mathrm{CO}$ on cobalt sites is faster than $\mathrm{C}-\mathrm{C}$ bond formation to $\mathrm{C} 2+$ oxygenates.

From characterization results, there are no major differences in reduction behavior and surface distribution among the three catalysts. This suggests that change of selectivity with time is due to reconstruction of the surface on the $\mathrm{CuCoLa} 2 \mathrm{O} 3$ catalyst that produces sites favorable to alcohols - both methanol and C2+ oxygenates. Such surface reconstruction of cobalt-copper particles in the presence of syngas has been reported by Yizhi et al. [28], who showed major Co surface segregation of the $\mathrm{Co}-\mathrm{Cu}$ particles took place during syngas exposure, and an "onionlike" graphitic carbon shell was observed on the particle surface. Lebarbier et al.[20] reported the effect of $\mathrm{La}_{2} \mathrm{O}_{3}$ on cobalt catalysts, claiming that exposure to $\mathrm{CO}$ leads to the formation of $\mathrm{Co}_{2} \mathrm{C}$ on the surface, thus Co exists in both metallic $\mathrm{Co}$ and $\mathrm{Co}_{2} \mathrm{C}$ phase. Reaction studies showed slightly increase in the alcohol selectivity was observed for the sample with highest $\mathrm{Co}_{2} \mathrm{C}_{/ \mathrm{Co}^{0}}$ ratio on the surface. Furthermore, Volkova et al.[29] proposed that $\mathrm{Co}_{2} \mathrm{C}$ is able to activate $\mathrm{CO}$ 
associatively and insert $\mathrm{CO}$ into $(\mathrm{CHx})_{\text {ads }}$ species that lead to higher alcohols. On CuCoLa2O3 here (Figure 4), the selectivity to $\mathrm{C}_{2+}$ hydrocarbons decreases while methanation rate increases, which could be caused by the formation of surface carbon or $\mathrm{Co}_{2} \mathrm{C}[30]$. The formation of carbon or cobalt carbide will decrease catalyst activity and increase methane selectivity [31, 32].

Figure 5 shows the TPO results to measure any carbon deposition on used CuCoLa2O3, $\mathrm{CuCoZrO} 2$ and $\mathrm{CuCoAl} 2 \mathrm{O} 3$ catalysts after 9 hours of reaction. The amount of carbon on the used $\mathrm{CuCoZrO} 2$ was much more than $\mathrm{CuCoLa} 2 \mathrm{O} 3$ or $\mathrm{CuCoA} 2 \mathrm{O} 3$. This clearly suggests that the relative low activity of the $\mathrm{CuCoZrO} 2$ is due to carbon deposition.

$\mathrm{CuCoZrO} 2$ and $\mathrm{CuCoAl} 2 \mathrm{O} 3$ shows similar TPO peaks between $200^{\circ} \mathrm{C}$ and $295^{\circ} \mathrm{C}$, but with much more of this carbon on $\mathrm{CuCoZrO} 2$, as measured by the area under the TPO peaks. $\mathrm{CuCoLa} 2 \mathrm{O} 3$ shows a shoulder at $230^{\circ} \mathrm{C}$, a larger peak at $320^{\circ} \mathrm{C}$ and another peak at $565^{\circ} \mathrm{C}$. Literature attributes the peaks in the $200-300^{\circ} \mathrm{C}$ region to the oxidation of polymeric carbon species for all three catalysts [33-35]. Cobalt carbide decomposes above $300^{\circ} \mathrm{C}[36]$, therefore, the peak around $320^{\circ} \mathrm{C}$ on the $\mathrm{CuCoLa} 2 \mathrm{O} 3$ catalyst can be assigned to the decomposition and oxidation of cobalt carbide. The $\mathrm{CuCoLa} 2 \mathrm{O} 3$ peak at $565^{\circ} \mathrm{C}$ corresponds to the decomposition of graphitic carbon on the surface [37, 38].

Lanthanum promoter in $\mathrm{CuCoLa} 2 \mathrm{O} 3$ seems to play a vital role in promoting the surface reconstruction and changing the product selectivity to favor alcohols. More in-situ characterizations are required to study the mechanism of surface reconstruction and formation of intermediates during syngas exposure, which will help us to further increase higher alcohols selectivity in $\mathrm{CO}$ hydrogenation reaction. The selectivity to ethanol and higher alcohols can also be further increased by adjusting reaction conditions. For instance, changing the $\mathrm{H}_{2} / \mathrm{CO}$ ratio to 
1/1 will decrease the methane and the methanol selectivity and favor the higher alcohols synthesis $[1,25]$.

\section{Conclusion}

No major difference in the catalyst reduction behavior is observed for these promoted catalysts during the TPR. The reduction of cobalt and copper are completed for all the catalysts by $300^{\circ} \mathrm{C}$, which is consistent with literature. $\mathrm{XRD}$ results show $\mathrm{CuO}$ and $\mathrm{Co}_{3} \mathrm{O}_{4}$ phases in the fresh, calcined catalysts. The samples show uniform particles which have the same $\mathrm{Cu} / \mathrm{Co}$ ratios on the surface and in the bulk. In the activity tests, $\mathrm{CuCoAl} 2 \mathrm{O} 3$ displayed highest $\mathrm{CO}$ conversion, while $\mathrm{CuCoLa2O} 3$ yielded much higher carbon selectivity to methanol (16.9\%) ethanol $(10.5 \%)$ than the other two tests. All three catalysts showed changes with time-onstream, with more significant increases in methanation and methanol formation compared to other products. Increases in selectivity were particularly significant for $\mathrm{CuCoLa} 2 \mathrm{O} 3$, suggesting the existence of surface reconstruction and intermediate formation on the surface during the exposure of syngas. Post-reaction TPO detected polymeric carbon on all used catalysts, while $\mathrm{CuCoZrO} 2$ showed highest polymeric carbon accumulation. TPO also showed the existence of cobalt carbide on spent CuCoLa2O3.

The addition of the three metal promoter oxides leads to significant differences. Specifically, the $\mathrm{C}_{1}-\mathrm{C}_{6}$ alcohol selectivity for the $\mathrm{CuCoLa} 2 \mathrm{O} 3$ (34.9\%) is far greater than either CuCoAl2O3 (13.1\%) or CuCoZr2O4 (17.8\%). This suggests fundamental reasons for CuCoLa2O3, Perhaps the surface basicity is increased by Lanthanum oxide to favor alcohols formation [39]. Another difference for CuCoLa2O3 is the hydrocarbon selectivity. The difference in $\mathrm{C}_{2}-\mathrm{C}_{6}$ hydrocarbon selectivity between the $\mathrm{CuCoAl} 2 \mathrm{O} 3$ (26.0\%) and $\mathrm{CuCoZrO} 2$ (29.6\%) on one hand, and CuCoLa2O3 on the other hand (14.4\%) appears to reflect that on 
$\mathrm{CuCoLa} 2 \mathrm{O} 3$ the relative rates of the hydrogenation of surface $\mathrm{CH}_{\mathrm{x}}$, to hydrocarbons is lower than the relatively rates of the hydrogenation of the $\mathrm{CO}_{\mathrm{ads}}-\mathrm{CH}_{\mathrm{x}}$ bond to $\mathrm{C}_{2}{ }^{+}$alcohols $[2,17,25]$. The metal promoter oxides studied here clearly affect the formation of the final products on the associative and dissociative adsorption sites, and La in particular promotes the selectivity to oxygenates versus hydrocarbons.

\section{Acknowledgements}

This material is based upon work supported as part of the Center for Atomic Level Catalyst Design, an Energy Frontier Research Center funded by the US Department of Energy, Office of Science, Office of Basic Energy Sciences under Award Number DE-SC0001058. A part of this study was conducted at the Center for Nanophase Material Sciences, which is sponsored at Oak Ridge National Laboratory by the division of Scientific User Facilities, US Department of Energy. The authors are thankful to Dr. Viviane Schwartz and Dr. Jong Kahk Keum for setting up in situ XRD experiments. The help of Kimberly Hutchison from North Carolina State University, Department of Soil Science on ICP-OES analysis is gratefully acknowledged. 


\section{References}

[1] M. Gupta, M.L. Smith, J.J. Spivey, Acs Catalysis 1 (2011) 641-656.

[2] V. Subramani, S.K. Gangwal, Energy \& Fuels 22 (2008) 814-839.

[3] N. L. Holy, T. F. Carey Jr, Applied Catalysis 19 (1985) 219-223.

[4] P. Gronchi, E. Tempesti, C. Mazzocchia, Applied Catalysis A: General 120 (1994) 115126.

[5] J. Hu, Y. Wang, C. Cao, D.C. Elliott, D.J. Stevens, J.F. White, Catalysis Today 120 (2007) 90-95.

[6] L. Han, D. Mao, J. Yu, Q. Guo, G. Lu, Applied Catalysis A: General 454 (2013) 81-87.

[7] K. Fang, D. Li, M. Lin, M. Xiang, W. Wei, Y. Sun, Catalysis Today 147 (2009) 133-138.

[8] P. Courty, D. Durand, E. Freund, A. Sugier, Journal of Molecular Catalysis 17 (1982) 241-254.

[9] N. Mouaddib, V. Perrichon, M. Primet, Journal of the Chemical Society, Faraday Transactions 1: Physical Chemistry in Condensed Phases 85 (1989) 3413-3424.

[10] M.L. Smith, N. Kumar, J.J. Spivey, The Journal of Physical Chemistry C 116 (2012) 7931-7939.

[11] Y. Xiang, V. Chitry, P. Liddicoat, P. Felfer, J. Cairney, S. Ringer, N. Kruse, Journal of the American Chemical Society 135 (2013) 7114-7117.

[12] A. Sugier, E. Freund, U.S. Patent 4291126 (September 1981).

[13] A. Sugier, E. Freund, U.S. Patent 4122110 (October 1978).

[14] A. Sugier, E. Freund, J.L. Page, U.S. Patent 4346179 (August 1982).

[15] P. Courty, D. Durant, A. Sugier, E. Fremund, U.S. Patent 4,659,742 (April 1978).

[16] A. Sugier, E. Freund, P. Courty, D. Durand, F. Edouard, 4659742 April 1987 (April 1987).

[17] G. Prieto, S. Beijer, M.L. Smith, M. He, Y. Au, Z. Wang, D.A. Bruce, K.P. de Jong, J.J. Spivey, P.E. de Jongh, Angewandte Chemie International Edition 53 (2014) 6397-6401.

[18] N.D. Subramanian, G. Balaji, C.S.S.R. Kumar, J.J. Spivey, Catalysis Today 147 (2009) 100-106.

[19] N. Mouaddib, V. Perrichon, G.A. Martin, Applied Catalysis A: General 118 (1994) 6372.

[20] V.M. Lebarbier, D. Mei, D.H. Kim, A. Andersen, J.L. Male, J.E. Holladay, R. Rousseau, Y. Wang, The Journal of Physical Chemistry C 115 (2011) 17440-17451.

[21] G. Jacobs, P.M. Patterson, Y. Zhang, T. Das, J. Li, B.H. Davis, Applied Catalysis A: General 233 (2002) 215-226.

[22] A.M. Hilmen, D. Schanke, K.F. Hanssen, A. Holmen, Applied Catalysis A: General 186 (1999) 169-188.

[23] J. Wang, P.A. Chernavskii, A.Y. Khodakov, Y. Wang, Journal of Catalysis 286 (2012) 51-61.

[24] J.F. Moulder, J. Chastain, R.C. King, Handbook of X-ray photoelectron spectroscopy: a reference book of standard spectra for identification and interpretation of XPS data, PerkinElmer Eden Prairie, MN, 1992.

[25] J.J. Spivey, A. Egbebi, Chemical Society Reviews 36 (2007) 1514-1528.

[26] J. Wang, P.A. Chernavskii, Y. Wang, A.Y. Khodakov, Fuel 103 (2013) 1111-1122.

[27] M. Ichikawa, T. Fukushima, Journal of the Chemical Society, Chemical Communications (1985) 321-323. 
[28] Y. Xiang, R. Barbosa, N. Kruse, ACS Catalysis 4 (2014) 2792-2800.

[29] G.G. Volkova, T.M. Yurieva, L.M. Plyasova, M.I. Naumova, V.I. Zaikovskii, J. Mol.

Catal. A-Chem. 158 (2000) 389-393.

[30] H. Karaca, O.V. Safonova, S. Chambrey, P. Fongarland, P. Roussel, A. Griboval-

Constant, M. Lacroix, A.Y. Khodakov, Journal of Catalysis 277 (2011) 14-26.

[31] G. Kwak, M.H. Woo, S.C. Kang, H.-G. Park, Y.-J. Lee, K.-W. Jun, K.-S. Ha, Journal of Catalysis 307 (2013) 27-36.

[32] M. Claeys, M.E. Dry, E. van Steen, E. du Plessis, P.J. van Berge, A.M. Saib, D.J.

Moodley, Journal of Catalysis 318 (2014) 193-202.

[33] D.J. Moodley, J. van de Loosdrecht, A.M. Saib, M.J. Overett, A.K. Datye, J.W.

Niemantsverdriet, Applied Catalysis A: General 354 (2009) 102-110.

[34] D.-K. Lee, J.-H. Lee, S.-K. Ihm, Applied Catalysis 36 (1988) 199-207.

[35] A.M. Saib, D.J. Moodley, I.M. Ciobîcă, M.M. Hauman, B.H. Sigwebela, C.J. Weststrate, J.W. Niemantsverdriet, J. van de Loosdrecht, Catalysis Today 154 (2010) 271-282.

[36] H.W. Pennline, R.J. Gormley, R.R. Schehl, Industrial \& Engineering Chemistry Product Research and Development 23 (1984) 388-393.

[37] Z. Pan, M. Parvari, D.B. Bukur, Applied Catalysis A: General 480 (2014) 79-85.

[38] I. Luisetto, S. Tuti, C. Battocchio, S. Lo Mastro, A. Sodo, Applied Catalysis A: General 500 (2015) 12-22.

[39] T. Ishida, T. Yanagihara, X. Liu, H. Ohashi, A. Hamasaki, T. Honma, H. Oji, T. Yokoyama, M. Tokunaga, Applied Catalysis A: General 458 (2013) 145-154. 


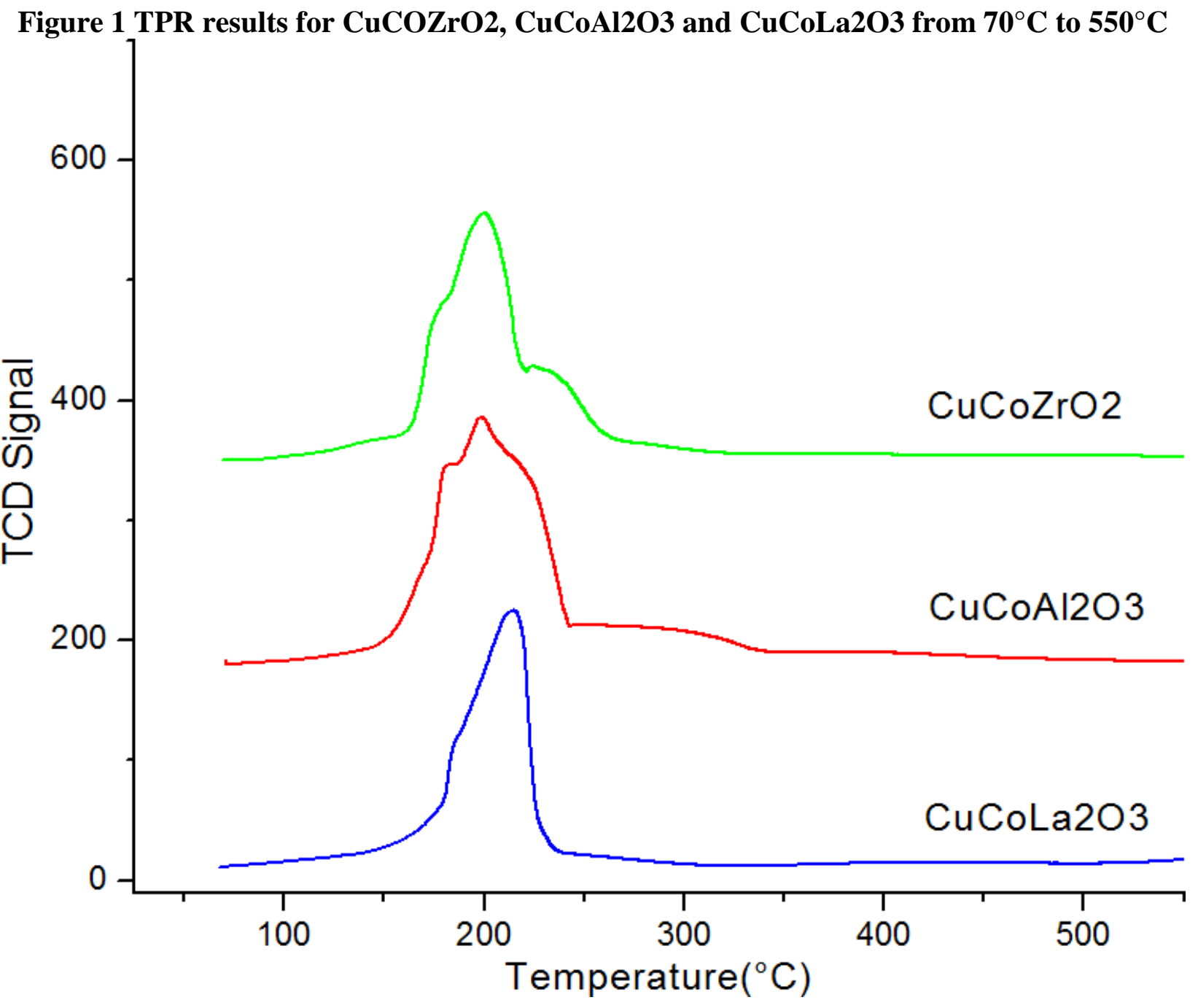


Figure 2 Characterization on calcined CuCoAl2O3, CuCoLa2O3 and CuCoZrO2 samples by XRD and XPS. (a) XRD patterns during reduction in $4 \% \mathrm{H}_{2} / \mathrm{He}$ at indicated temperatures for $\mathrm{CuCoAl}_{203}$; (b) XRD patterns during reduction in $4 \% \mathrm{H}_{2} / \mathrm{He}$ at indicated temperatures for $\mathrm{CuCoLa2O3}$; (c) XRD patterns during reduction in $4 \% \mathrm{H} / \mathrm{He}$ at indicated temperatures for $\mathrm{CuCoZrO2}$; (d) XPS spectra of Co 2p region for CuCoAl2O3, CuCoLa2O3 and CuCoZrO2 sample (e) XPS spectra of $\mathrm{Cu} 2 \mathrm{p}$ region for CuCoAl2O3, CuCoLa2O3 and CuCoZrO2 sample.
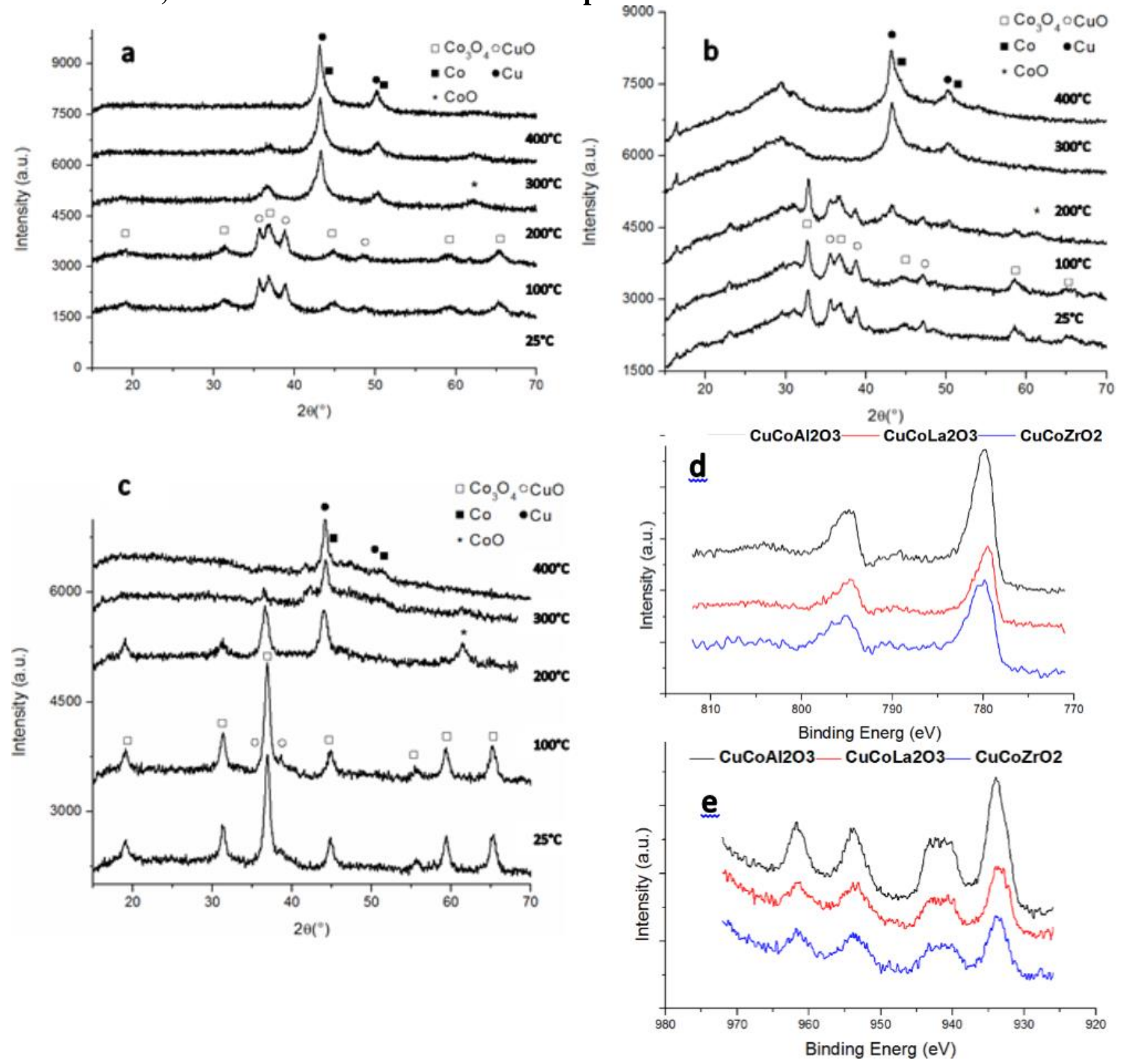
Figure 3. CO conversion as a function of time on stream of CuCoLa2O3, $\mathrm{CuCoZrO2} \mathrm{\&}$ $\mathrm{CuCoAl2O3}$ at $250{ }^{\circ} \mathrm{C}, 30 \mathrm{bar}$, and $\mathrm{GHSV}=36000 \mathrm{scc} / \mathrm{g}_{\mathrm{cat}} / \mathrm{h}$.

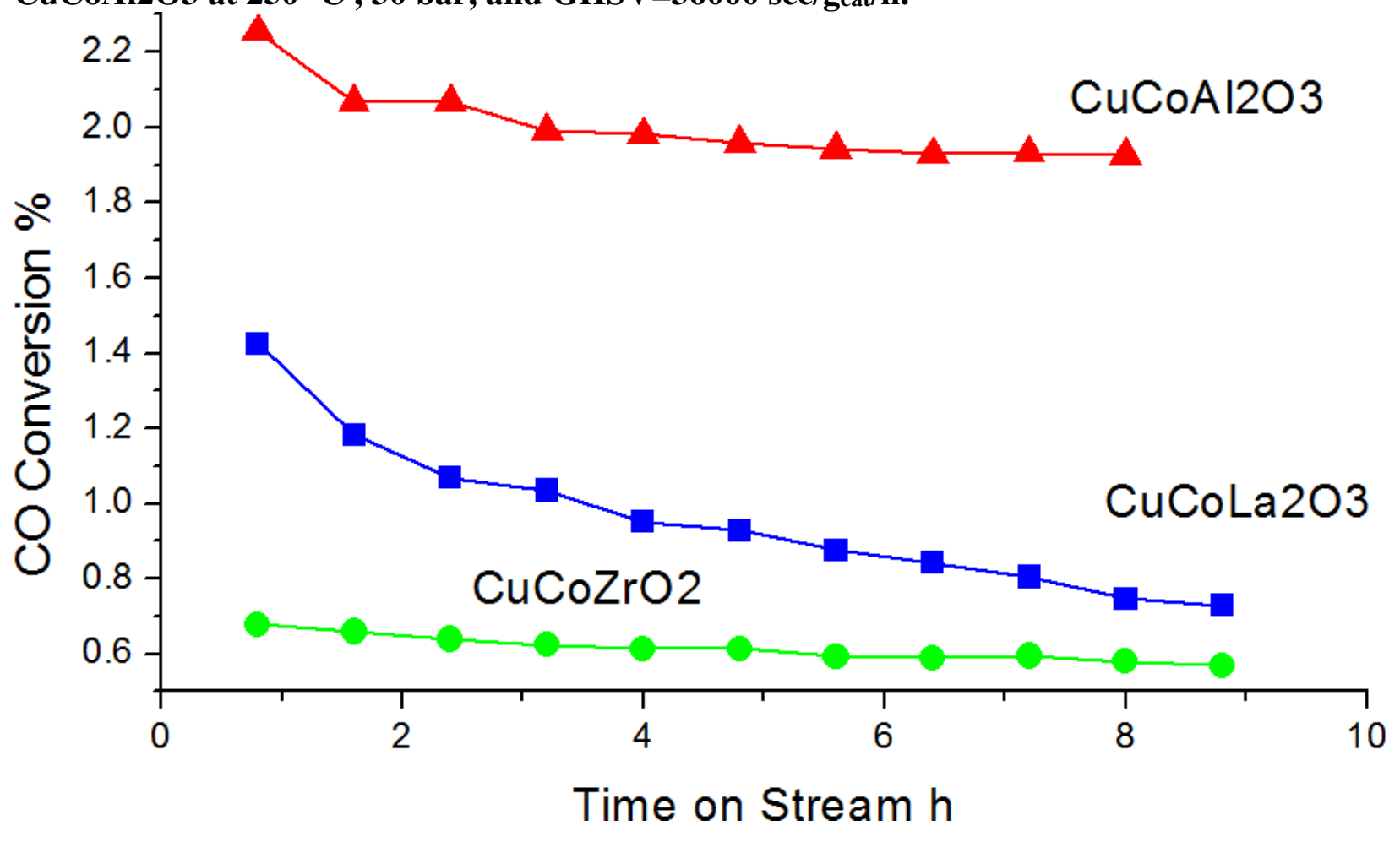


Figure 4 Selectivity changes as a function of time on stream on $\mathrm{CuCoLa2O3,} \mathrm{CuCoZrO2}$ and $\mathrm{CuCoAl} 2 \mathrm{O3}$ during reaction at $250^{\circ} \mathrm{C}$.
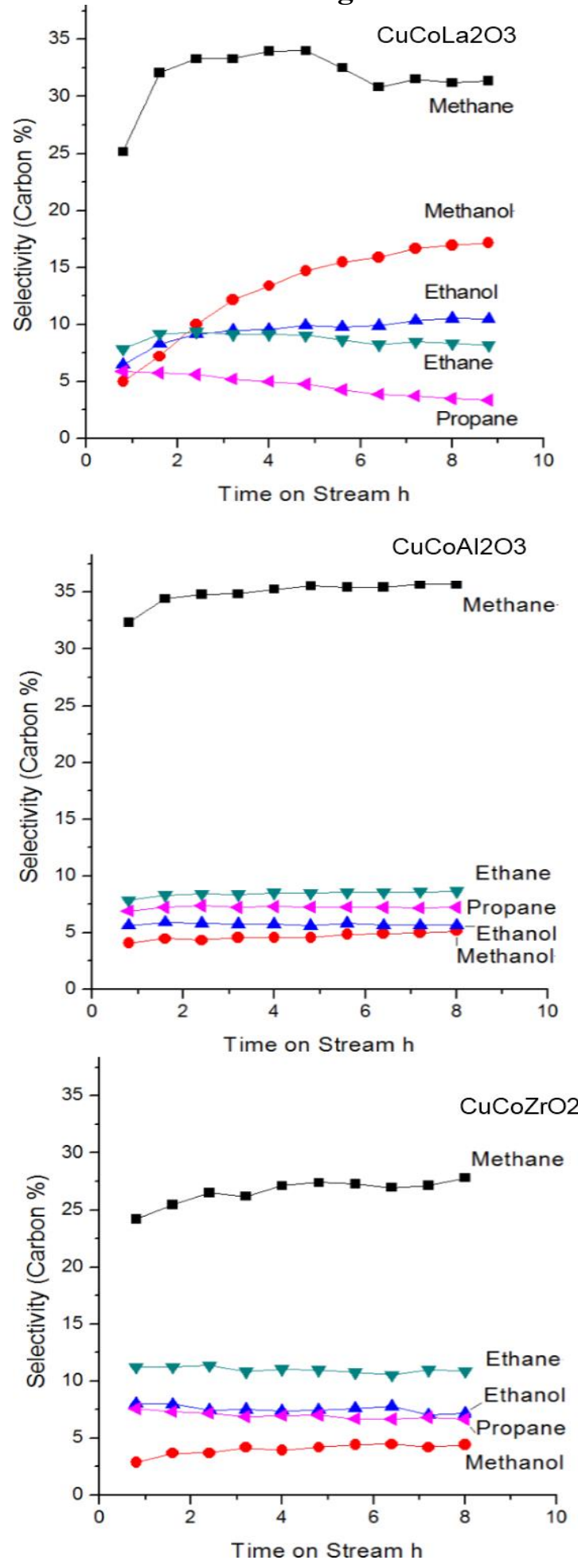
Figure 5 TPO of CuCoLa2O3 and CuCoAl2O3 after $\mathrm{CO}$ hydrogenation Reaction at $250{ }^{\circ} \mathrm{C}$ for 9 hours.

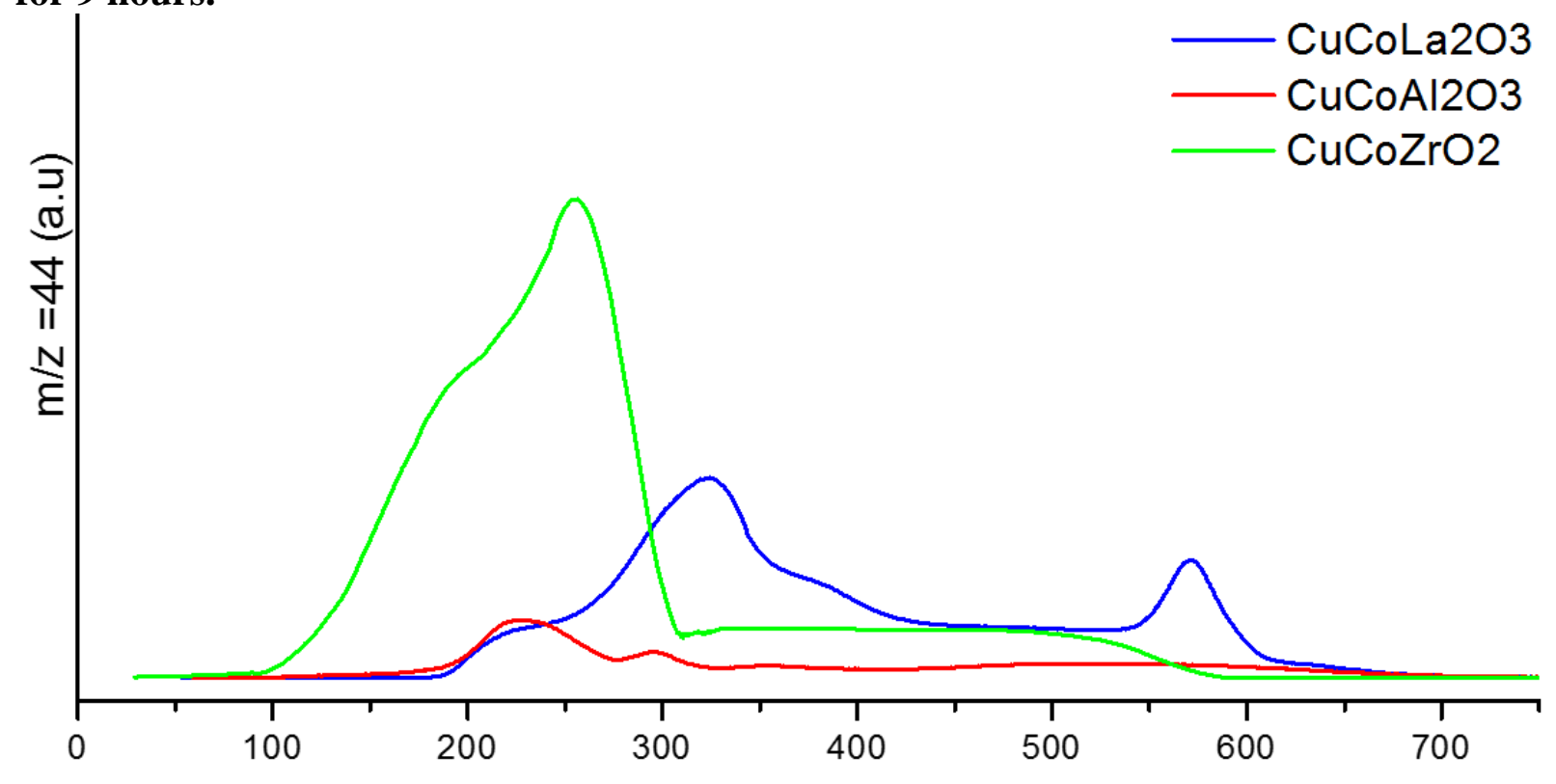


Table 1 Catalyst composition by ICP-OES and BET surface area ${ }^{\text {a }}$

\begin{tabular}{|c|c|c|c|c|}
\hline \multirow{2}{*}{ Catalyst } & \multicolumn{2}{|c|}{ Composition (wt\%) } & \multirow{2}{*}{$\begin{array}{c}\mathrm{Cu} / \mathrm{Co} \text { molar } \\
\text { ratio }\end{array}$} & \multirow{2}{*}{$\begin{array}{c}\text { Surface Area } \\
\mathrm{m}^{2} / \mathrm{g}\end{array}$} \\
\hline & $\mathrm{Co}$ & $\mathrm{Cu}$ & & \\
\hline $\mathrm{CuCoA} 12 \mathrm{O} 3$ & 26.6 & 32.0 & 1.11 & 94.1 \\
\hline $\mathrm{CuCoLa} 2 \mathrm{O} 3$ & 18.8 & 23.3 & 1.14 & 49.7 \\
\hline $\mathrm{CuCoZrO} 2$ & 25.7 & 30.4 & 1.09 & 88.8 \\
\hline
\end{tabular}

a. The molar ratio of $\mathrm{Cu}: \mathrm{Co:Metal} \mathrm{oxide(Al2O3,} \mathrm{La2O3} \mathrm{and} \mathrm{ZrO2})=2: 2: 1$. 
Table 2 Quantitative H2 Consumption During TPR ${ }^{\text {a }}$

\begin{tabular}{cccc}
\hline Catalyst & $\mathrm{H} 2$ consumed $(\mu \mathrm{mol} / \mathrm{g})$ & Expected consumption $(\mu \mathrm{mol} / \mathrm{g})$ & Metal reduced \% \\
\hline $\mathrm{CuCoA12O} 3$ & $291 \pm 6$ & 314 & $92.7 \pm 2.0$ \\
$\mathrm{CuCoLa} 2 \mathrm{O} 3$ & $235 \pm 3$ & 241 & $97.5 \pm 1.2$ \\
$\mathrm{CuCoZrO} 2$ & $294 \pm 5$ & 305 & $96.4 \pm 1.6$ \\
\hline
\end{tabular}

a. Errors in the $\mathrm{H} 2$ consumption values are within $95 \%$ confidence interval. 
Table 3 XPS Binding Energies and Surface Composition Analysis

\begin{tabular}{|c|c|c|c|c|}
\hline \multirow{2}{*}{ Catalyst } & \multicolumn{2}{|c|}{ Binding Energies } & \multirow{2}{*}{$\begin{array}{l}\mathrm{Cu} / \mathrm{Co} \text { atomic } \\
\text { ratio by XPS }\end{array}$} & \multirow{2}{*}{$\begin{array}{l}\mathrm{Cu} / \mathrm{Co} \text { atomi } \\
\text { ratio by ICP }\end{array}$} \\
\hline & $\mathrm{Cu} 2 \mathrm{p} 3 / 2$ & Co $2 p 3 / 2$ & & \\
\hline $\mathrm{CuCoAl} 2 \mathrm{O} 3$ & 933.8 & 779.7 & 1.17 & 1.11 \\
\hline $\mathrm{CuCoLa} 2 \mathrm{O} 3$ & 933.6 & 779.5 & 1.23 & 1.14 \\
\hline $\mathrm{CuCoZrO} 2$ & 933.6 & 779.8 & 1.09 & 1.09 \\
\hline
\end{tabular}


Table 4 Activity \& Products Selectivity for CuCoAl2O3, CuCoLa2O3 and $\mathrm{CuCoZrO2}$ at $250{ }^{\circ} \mathrm{C}$ and 30 bar $^{\mathrm{a}}$

\begin{tabular}{|c|c|c|c|c|c|c|c|}
\hline \multirow[b]{2}{*}{ Catalyst } & \multicolumn{6}{|c|}{ Carbon Selectivity } & \multirow{2}{*}{$\begin{array}{c}\mathrm{CO} \\
\text { Conversio } \\
\mathrm{n} \\
(\%)\end{array}$} \\
\hline & $\begin{array}{c}\text { Methan } \\
\text { e }\end{array}$ & $\begin{array}{c}\text { Methano } \\
1\end{array}$ & $\begin{array}{c}\text { Ethano } \\
1\end{array}$ & $\begin{array}{c}\mathrm{C}_{3-6} \\
\text { Oxygenate } \\
\mathrm{S} \\
\end{array}$ & $\begin{array}{c}\mathrm{C}_{2-6} \\
\text { Hydrocarbo } \\
\mathrm{n}\end{array}$ & $\mathrm{CO}_{2}$ & \\
\hline $\begin{array}{c}\mathrm{CuCoA} 12 \mathrm{O} \\
3\end{array}$ & 35.63 & 5.02 & 5.66 & 2.38 & 26.06 & $\begin{array}{c}23.2 \\
5\end{array}$ & 1.93 \\
\hline $\begin{array}{c}\mathrm{CuCoLa} 2 \mathrm{O} \\
3\end{array}$ & 31.37 & 16.92 & 10.46 & 7.47 & 14.45 & $\begin{array}{c}18.0 \\
3\end{array}$ & 0.76 \\
\hline $\mathrm{CuCoZrO} 2$ & 28.14 & 4.35 & 7.32 & 6.09 & 29.63 & $\begin{array}{c}22.6 \\
7\end{array}$ & 0.58 \\
\hline
\end{tabular}

a. Selectivity and CO conversion were taken at near steady state after 9 hours of reaction. 